UNIO - EU Law Journal. Vol. 4, No. 1, January 2018, pp 133-143.

®2018 Centre of Studies in European Union Law

School of Law - University of Minho

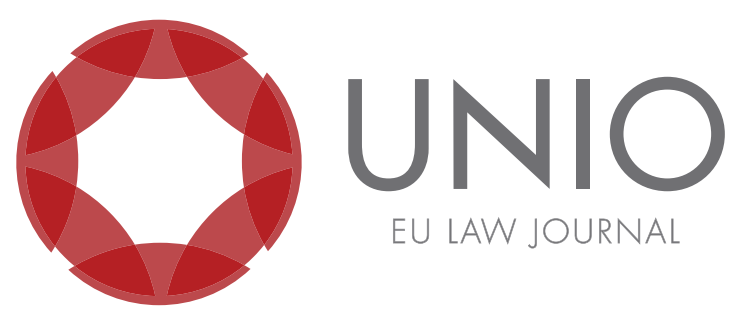

\title{
Problems and solutions to access to documents in sanction proceedings - judicial ruling in the Competition, Regulation and Supervision Court of Santarém, Portugal.
}

\begin{abstract}
Alexandre Leite Baptista*
ABSTRACT: This article analyzes the recent judicial practice of the Competition, Regulation and Supervision Court in relation to interlocutory measures of the Portuguese Competition Authority, concretized in the interpretation and application of Articles 30 (Business secrets), 31 (Proof), 32 (Publicity of the case and secrecy of justice) and 33 (Access to the process), all of the Novo Regime Juridico da Concorrência, approved by Lei n. 19/2012, of 08 May, and through the formulation of rules of procedural action in the guarantees of access to documentary evidence in the respective sanctioning process.
\end{abstract}

KEYWORDS: Business secret - exculpatory value - inculpatory value - access regime.

\footnotetext{
* Judge in the Competition, Regulatory and Supervisory Court of Portugal
} 
"No meio do caminho tinha uma pedra Tinha uma pedra no meio do caminho..."

Between 2015 and 2017, the Competition, Regulation and Supervision Court (CRSC) of Santarém, in Portugal, received successively and sequentially a series of appeals for the judicial review of interlocutory measures of the Portuguese Competition Authority (PCA), adopted in sanction proceedings concerning anticompetitive practices within the scope of the Novo Regime Juridico da Concorrencia (NRJC), approved by Law $n^{\circ} .19 / 2012$, of $08^{\text {th }}$ May.

The nerve center of these objections pointed to the legality of PCA's interlocutory decisions regarding the access of co-defendants to documents available in the process, with business secrets or confidential value, seized from the other codefendants.

Judicial ruling concerns, therefore, the interpretation and application of Articles 30 (Business secrets), 31 (Proof), 32 (Publicity of the case and secrecy of justice) and 33 (Access to process), and all of the NRJC, with reference to Articles 18 (Powers of inquiry, search and seizure); 20 (Seizure) and 25 (Instruction of the case) of the same regime.

The problem also calls for the collation of the following elements of hermeneutic context: (i) Guidelines for the Instruction of Processes related to the application of Articles 9, 11 and 12 of the NRJC and Articles 101 and 102 of the TFEU of 22 March 2013 adopted by the PCA under its regulatory powers; (ii) Commission Regulation (EC) N. 773/2004 of 7 April 2004 relating to the conduct of proceedings by the Commission pursuant to Articles 101 and 102 of the Treaty on the Functioning of the European Union; ${ }^{3}$ (iii) Commission notice on the rules for access to the file in cases concerning the application of Articles 81 and 82 of the EC Treaty, Articles 53, 54 and 57 of the EEA Agreement and Regulation (EC) N. 139/2004 as amended in 2015 (2015C 256/03, OJEU of 05.08.2015); (iv) The ruling of the Court of First Instance of 29 June 1995, European Commission, Case T-30/91; (v) Judgment of the Lisbon Commercial Court, handed down in case N. 766/06.4TYLSB, by the Honorable Judge Maria José Costeira.

The quid juris of the practical case (in its original form) is based on the following premises:

- In the context of sanction proceedings for infringements in the field of restrictive practices, PCA undertakes the search, examination, collection and seizure of several documents and various media at the premises of companies involved in the proceedings;

- These proceedings of probation lead to a special case complexity, in the

\footnotetext{
${ }^{1}$ Carlos Drummond de Andrade, first verses of the poem "No meio do caminho", roughly translated as

"In the middle of the way there was a stone/There was a stone in the way".

${ }^{2}$ Pursuant to $\$ 187$ : documents containing items of information which are considered confidential for reasons of business secrecy and correspondence between the Competition Authority and the entities holding such information and which the Authority does not consider necessary for proof of the infringement, shall be attached to the case file, which is not accessible to the persons referred to by the file or to third parties, duly identified as containing confidential information. A list drawn up by the investigation team, identifying the documents considered as confidential and summarily summarizing the reasons for such qualification, may be obtained directly from the documents in the file and accessible to all defendants or third parties.

${ }^{3}$ Cf. Article 16(2) and (3), b) and c).

${ }^{4}$ Cf. paragraphs 37 and 38 .
} 
sense that tens of thousands of documents are seized, in computer media and paper;

- Only a part of the seized documentation is used in Statement of Objections (hereinafter, SO), while the remaining evidence collected, regardless of its exculpatory value is ignored;

- Articles 30; 31; 33(4) of the NRJC do not give any indication as to who is legally entitled to have access to the documents not considered for the SO. This, thereby, unwittingly creates an exploitable lacuna in the sense that there is no rule expressly regulating access to documents classified as confidential for reasons of business secrecy and not used by the PCA to attribute the infringement (even exculpatory);

- The PCA determines that access to the documental evidence not used in the $\mathrm{SO}$ is carried out on the same terms as the evidence used in the NI, as provided in Article 33(4) of the NRJC - access to all documentation by lanyers and advisors... external data of the visas, in a duly equipped data room, linking them to a confidentiality clause and probibiting the use of technical means of reproduction.

- The PCA denies co-defendants requests for generic/specific access to the documental evidence used in SO with inculpatory value and the documentary evidence seized with potential exculpatory value;

- The PCA denies co-defendants requests for the exclusion of documents not used in SO (attorneys communications, commercial information, etc ...);

- In those decisions, the PCA chooses as the decision's premises the need to carry out an exercise of practical agreement between the legitimate interest of undertakings in the protection of their business secrets and the co-defendants rights of defense.

- The co-defendants appealed these decisions, requesting the annulment of the interlocutory decisions taken by the PCA.

Configuring as a problem of access of co-defendants, in the sanctioning process, to confidential documents not used as evidence in the SO, potentially exculpatory, a solution has to be found by defining the rule of procedural access to documental evidence with confidential content by other co-defendants that are, at the same time, economic or commercial competitors with the holder or owner of the documents seized.

From almost two years of judicial ruling, after several decisions at $1^{\text {st }}$ and $2^{\text {nd }}$ instance, some still pending appeal, it may be useful to explore the evolution of these CRSC's rulings and to assess the good practices in these documental inquiries, searches and seizures towards the guarantee of the rights of the defense in the sanction proceedings regulated and provided in the NRJC. ${ }^{5}$

Let's review the chronology of these CRSC pronouncements throughout this period of interlocutory litigation: ${ }^{6}$

- Case N. 225/15.4YUSTR, 09/2015 ruling - This case dismissed the PCA's decisions on appeals that rejected the generic request of some

\footnotetext{
${ }^{5}$ As sanctioning processes are under way, the counter-ordering factuality in investigation is a negligible element for this analysis.

${ }^{6}$ Since the CRSC does not yet have a place to access and publish its decisions, the sentences can be consulted through informal requests for access to each of the sentences.
} 
co-defendants for access to all confidential documents not used by the Competition Authority in the $\mathrm{SO}$ as a means of proving the infringement;

- Case N. 1/16.7YUSTR, 02/2016 ruling $^{7}$ - This case upheld the appeal against the PCA's decision, so far as it allows unconditional and unrestricted access to documents seized from the one co-defendant classified as confidential and not relied upon by the PCA as evidence in the SO, without any specific requirement as a basis for the consultation request;

- Case N. 195/16.1YUSTR, 10/2016 ruling - This case dismissed, as unfounded, the appeal against the PCA'S decision requesting the identification of confidentiality of all information seized at the premises of the co-defendants, the preparation of summaries of confidential information and the preparation of non-confidential versions of documents considered to be partially confidential, in the part concerning the preparation of summaries of confidential information/documentation; second, it dismissed the appeal against the PCA's decision that rejected the request for exclusion of documents subject to professional secrecy and personal documents subject to privacy reserve, in particular information protected by bank secrecy without any relevance to the scope of the process, seized during the search and seizure proceedings;

- Case N. 195/16.1YUSTR-B, 12/2016 ruling - This case dismissed the appeal against the PCA's decision requiring the co-defendants to review the reasons for the confidentiality classification of the information seized in the search and seizure proceedings;

- Case N. 291/16.5YUSTR, 12/2016 ruling - This case jettisoned the appeal against the PCA's decision, which rejected a request to make a copy of the documents used in the SO available to the defendant agents/ economic advisers;

- Case N. 337/16.7YUSTR, 01/2017 ruling - upheld the appeal against the PCA's decision that prevented the co-defendants' access to the full content of some documents referred in the $\mathrm{SO}$;

- Case N. 194/16.3YUSTR, 01/2017 ruling - partially upheld the appeal of the PCA's decisions that requested the preparation of summaries of the confidential documentation seized in the search and seizure proceedings, partially repealing the decision to the effect that the "summary" applies only to fully confidential documents, the period of forty working days commencing, after a further notification by the Board of Directors to that effect, with the warning that its non-compliance will mean, in accordance with the of Article 30(4), of the NRJC; finally, the case dismissed the appeal against the PCA's decision that rejected the request to exclude legally included documentation;

- Case N. 20/16.3YUSTR, 03/2017 ruling - This case dismissed as unfounded, the appeal against the PCA's decision rejecting the request to access and to consult uncovered information relating to the request for exemption; second, it dismissed the appeal against the PCA's decision that rejected the application for joinder of other proceedings pending against

${ }^{7}$ This ruling was subsequently annulled by the Court of Appeal of Lisbon (second instance court) for lack of jurisdiction and then, after being joined to case $n^{\circ}$. 225/15.4YUSTR-A, was fully upheld by the subsequent decision and confirmed by the same superior Court. 
the same co-defendants; third, it dismissed the appeal against the PCA's decision that rejected the applicant's request to exclude from the file all personal information, customer information, information relating to legal advice and communications with lawyers and auditors, as well as general information relevant to the case and proceedings; finally, it dismissed the appeal against the PCA's decision that rejected the applicant's request for a full copy of the consultable version of all the documents in the proceeding;

- Case N. 225/15.4YUSTR-B, 06/2017 ruling - This case dismissed the appeals against the PCA's decisions that suspended the access to documents in a data room, removed from documents seized from the applicant of Process N. 225/15.4YUSTR-A. ${ }^{8}$

Taking advantage of the communicational simplicity in eschatological discourse, the jurisprudential synthesis of this conflict between the defendant's rights of defense and the legitimate interest of third parties/co-defendants in safeguarding the nondisclosure of their respective business secrets can be expressed in 7 Commandments of the Regime of Business Secrets. These are the following:

\section{The PCA shall protect confidential information through the regime of access to confidential documents provided in Articles 30 to 33 of the NRJC.}

On the one hand, the CRSC illuminates the assertion that, pursuant to Article 30(1) of the NRJC, that the PCA has a guaranteed function of protecting business secrecy; so that the duty laid down therein must establish a compulsory interest, even if it is not prevailing, following a non-unconstitutional judgment of the prohibition of reproduction in Article 33 (4) (limited access and without reproduction of documents with inculpatory value); and in Article 81 (2) (access to a dispensation request), of the same regime.

On the other hand, it should be pointed out that, if the confidentiality of the information does not detract from the probative value of the respective documents, the duty to protect the interest in the preservation of business secrets in the proceedings related to restrictive practices does not disappear before the value information. Consequently, the special circumstances of each case must, first of all, comply with administrative principles of subsidiarity, minimum intervention and prohibition of excess over cross-cutting values such as the protection of confidential information not used as evidence and with potential exculpatory value.

\section{The PCA will not decide about the validity of the probative measures or legality of the documents seizure.}

The applicants seek repeatedly to indicate the legality and validity of the documents obtained during the seizing proceedings.

The CRSC responds that the material competence to assess the validity and legality (for excess and violation of warrants) of probative proceedings is a matter of criminal investigation and is unattainable in the sanctioning process, as is also

${ }^{8}$ Since the ruling rendered in Case N. 225/15.4YUSTR-A was final, the PCA complied with it only for the applicant in that case, without changing the access regime for the other co-defendants. 
the case in Article 21 of the NRJC, which also functions as a standard of material competence.

In fact, the probative evidence underlying the validity of the investigations of the sanctioning process is not to be confused with the subsequent judgments on the usefulness, pertinence and adequacy of such evidence in order to prove the facts established in the meantime.

However, it is based on the legality (and intangibility) of those steps, that it can be acknowledged that there is an increased duty to manage and process those documents and at a time prior to the granting of access by the co-defendants.

\section{The PCA must allow the co-defendants to control the confidentiality classification decisions taken by the PCA and its judgment of definitive or final probative relevance.}

It is a question of concretizing or enhancing the dimension of the right to a fair hearing, recognized by the Court of First Instance of the European Union in Case T-30/91, Solvay, by means of the general principle of equality of arms, which presupposes, that the undertaking in question has the same knowledge as the Commission of the documents used in the file. What we want to point out is that the contradictory and access to evidence of the case can also address the very criterion that was the origin of the classification, since it is this classification that will imply, later, an encumbrance or, at least, a restriction on the right of free consultation of all documents subject to the sanction investigation. Thus, the CRSC reiterates the assertion that "even though it is first hand for the PCA to examine the documents and to classify them as confidential, it does not means that such an analysis can't be verified, which must be, in theory, by the defendant and the Court' - in this sense, cf. ruling of the Lisbon Court of Commerce of 15 February 2007 in case 766/06.4TYLSB Nestlé (p. 94).

\section{The PCA must develop a descriptive and detailed list of documentary evidence with business secrecy value in order to allow an effective exercise of the defense rights through the access regime.}

If the first three commandments are merely enunciated, this assumes a more performative character of the PCA acting.

Here, the sequence is notoriously subsidiary to the previous commandments, although it reflects the contribution of the procedural rules expressly contained in the legal regime. Therefore, if document searches and seizures and other written material are carried out, the PCA should promote, with the collaboration of the defendant, the identification of documents that may integrate the concept of business secrets in order to facilitate their protection from unauthorised access, as provided for in Article 30(2) and (3) of the NRJC; and if the lack of collaboration or motivation of the defendant assumes the non-confidentiality of the information - Article 30(4) - and if the PCA may disagree with the classification and the request for confidentiality, then Article 30 (5) of the NRJC; the CRSC is peremptory when it states that the PCA, when it defines the access regulation to the document files, even if due to the prevalence of the defense rights and procedural speed, must first provide a sufficient description of the documents seized, in order to guarantee that the defendant's access is done in an informed manner, allowing 
an understanding of its contents for the purpose of its exculpatory use.

With regards to confidential access to documents which contain business secrets, this right must be made compatible with a safeguard for business secrets. Such compatibility can't be achieved with an immediate, indiscriminate and, therefore, unfound access to all the documents classified as confidential documents by the PCA. It must be based on the provision of information that enables the defendants to understand the content of the suppressed information and the correctness of the decision that deemed those documents confidential as well as their possible exculpatory relevance in order to formulate requests for access to concrete and as far as possible, founded.

The search for the casuistic solution by the CRSC goes inexorably along the path of practical agreement.

Thus, the ruling of agreement between protection of business secrecy and the rights of the defence always demands that the PCA, while domina of the investigation phase and as a fiduciary, is responsible for the documents seized, and for attending to requests for a consultation in order to help defendants to gain a reasonable understanding of the documents' contents, in terms such as the access isn't made by default or in a generic manner.

If the elements and context, mentioned above, serve as a duty source, the CRSC has been particularly important in the procedural imputation of this duty of diligence to the PCA, which considers it as an equaliser between ensuring appropriate access and preventing excessive, indiscriminate access, without regard for, inter alia, business secrecy.

\section{The PCA may exclude and return documents considered irrelevant, innocuous and unnecessary.}

Less imperative and more permissive, here we have a rule of action that, to a certain extent, represents the evolution of the first pronunciations and that seeks to overcome the natural contingencies inherent in the complexity of crossing multiple co-defendants' requirements for access to an extensive compendium of documentary evidence.

The CRSC emphasizes, prima facie, the difference between the assumptions that must govern the granting of evidence diligences of an invasive nature at an early stage of the proceedings, and the assumptions which, following the establishment and thoroughness of the evidence diligences, must preside over the circumstantial ruling on the merits of maintaining such evidence in the proceedings.

This is followed by the assertion that the maintenance of documents validly seized is a posterior ruling made after the probationary initial diligences, which depend on the subsequent verification of the usefulness of these documents as a means of proving facts with a sanctioning relevance, being that the returning of innocuous documents is an admissible expedient, although it is not the only one capable of providing for the safeguarding of business secrets.

With some care, the maintenance ruling versus documents devolution is safeguarded and due to their probative relevance or irrelevance, should not be imposed by the Court at a time prior to the investigation decision provided for in Article 24 of the NRJC, which concludes for the SO, without prejudice of this being carried out by the PCA at any time and within the reach of its management and investigation powers.

Therefore, one must concede to some degree of practical agreement that $\mathbf{a}$ 
decision on the validity of the investigating diligences is not tantamount to a decision on the relevance/irrelevance of that evidence by confrontation with other evidence and facts. Adding that kind of ruling is taken all the time by the criminal judicial authorities that investigate crimes (in which, as guarantees of a fair trial, they are more assertive) in respect of the due process.

Consolidated commandment II in the axiom, according to which the exclusion decided by the PCA isn't equivalent to knowing the law's compatibility with the seizure diligences and with the object of the seizure warrant, it is emphasized that the PCA has exclusive competence to conduct the investigation, as well as to determine the relevance of the evidence, and may order the exclusion of documentation irrelevant to the subject matter of the proceeding.

\section{The collaboration provided in Article 30, paragraphs 2} and 3 of the NRJC, configure the procedural burden of defense of the defendants.

This command also embodies a pronunciation version 2.0. of the original decisions on requests for access.

As we have seen, the regular fulfillment of Article 30, paragraphs 2 and 3 of the NRJC, is intended to safeguard the prevalence of the right to exercise its defense, even though the Court concedes that decisions on access to documents with business secrets must also observe the duty to take care of the efficiency, economy and speed of the investigation, in order to guarantee the reasonable time of the sanction process.

In this respect, the CRSC invests in the understanding, of a pragmatic nature, ensuring that one can avoid the consequence of an indiscriminate or less protective access to business secrets if the PCA has a proficient descriptive document that allows a more assertive decision on the deferral of access.

As such, the description can't underestimate, ignore or dispense the co-defendants' collaboration, under the risk of dimming the sanctioning process of the NRJC.

Hence, the CRSC enunciates, through Article 30, paragraphs 2 and 3 of the NRJC, some burdens attributable to the defendant concerned and interested in the protection of business secrets: $i$ ) the burden of identifying the information it considers to be confidential; ii) the burden of proof of such identification; iii) and the burden of providing a non-confidential copy of documents containing confidential information purged from them. ${ }^{10}$

\footnotetext{
${ }^{9}$ The CRSC constructs the respective arguments based on the following basic grounds: i) compliance with Article 30(2) of the NRJC, clearly states the need to stop the progress of the process in order to protect information that may contain business secret; (ii) the cooperation of the person concerned in the construction of a confidential information protection system, while at the same time, is not unreasonable, arbitrary or excessive in the light of the validity of the guarantee interest; (iii) the subjection of an undertaking to a sanctioning procedure will always imply the compression of its normal activity and the allocation of means in the measure of the management of its procedural and substantive interests; (iv) the call does not, per se, give rise to any breach of the principle of prohibition of self-incrimination or of nemo tenetur se ipsum accusare; v) Article 30(2) of the NRJC, does not matter so much for the instructional activity as it matters for safeguarding the business secret in sanctioning processes, purpose and the scope of the legal disposition.

${ }^{10}$ Regarding respect for administrative discretion, there is a clear case-law divergence between the decisions of Cases N. 195/16.1YUSTR and N. 194/16.3YUSTR on the extension and practical implementation of the requirement to draw up descriptive summaries of the contents of the partially
} 
In this regard, the CRSC clarifies that the informed identification of information serves, understands and reaches the content of the decision to prepare summaries of confidential information/documentation, submitting the omission of such collaboration to the procedural consequence of the final part of Article 30(2) of the NRJC, and that within teleology and with respect to the letter of the law, specifically the concept of "non-confidential copy", is included the burden of preparing a summary description of the deleted information content, for each document, as it is intended to enable the understanding of its content without the detail of business secrets.

The CRSC perspective follows a path that can be translated into syllogistic reasoning (despite the lack of cadence of 2 premises): if the PCA has a duty to pursue and guarantee the protection of business secrets as an accomplishment for the purpose of pursuing the public interest and defense of competition; if the protection of business secrecy is a fundamental interest in the fulfillment of their duties of custody and protection of documents in the sanctioning process; if, at the same time, the PCA must take care of the publicity and speed of the process in respect of the rights of defense; if the elaboration by the defendants of the proficient descriptive document accomplishes and guarantees, in better practical agreement, the regime of access to seized confidential documentation; if the protection of business secrets serves the interests of those involved, protecting confidential information from the access of potential competitors; if the confidentiality classification of such documents can only be achieved by the collaboration of the defendants, the discretionary conformation of whatever collaborative identification is based should give priority to administrative acts which give it useful, necessary, proportionate and relevant content for achieving the stated aim, preparation of detailed summaries of the information.

\section{PCA will not treat similarly access to confidential documents and the access of unused confidential documents that may contain business secrets.}

It is, in essence, a rule of synthesis of the CRSC judicial pronouncements of the thema decidendum.

The problem regarding the legal loophole of Article 33(4) of the NRJC and for documents not used in SO (with business secret value) is, above all, a formal problem of normative interpretation.

The publicity of the process is an original and top-of-the-line value (cf. Article 32 of the NRJC) of the organization of the process along with the speed of realization of the fair process, and, while the right of defense can be understood as a corollary of the value of the publicity of the process, the duty set forth in Article 30(1) of the NRJC, functions as an exception or circumscription of that free access.

The PCA, in the vestments of domina of the investigative and fiduciary phase of the seized documents, when it defines the regulation of access to the process, even if by the prevalence of the right to the defense and the speed of the process, cannot treat the confidential information with potential exculpatory value in the same way that it treats the confidential information with inculpatory value, considering the risk of compromising the duty provided by Article 30,

confidential documents, in addition to the preparation of a summary description of the information identified as confidential. 
the disclosure of which is liable to seriously prejudice the interests of the codefendants and third parties.

The absence of any prior control mechanism of this consultation, in terms of motivation and adequacy to the defense exercise being the same, feasible and possible with the preparation of the descriptive lists, causes that the PCA promotes, with the extension of Article 33 (4) of the NRJC, an indiscriminate access to confidential documents by the others is created, depriving it of its duty of caution in the nondisclosure of business secrets.

Of course, the CRSC assumes the dialectical tension that the ruling of practical agreement can involve. In fact, the duty stipulated by Article 30(1) of the NRJC, contains principles of the PCA's action that are diametrically opposed to the defendants' obligation to subject to search and seizure diligences of information and documents.

If the announced guarantee function of the duty set forth in Article 30(1) of the NRJC, acquires proper fulfillment by assigning to the PCA a procedural fiduciary or custodial responsibility in the provision of the information on the result of the search and seizure, then this same procedural responsibility for the treatment and management of the seized documents stems from the degree of interference and subjection due to the greater aggressiveness in terms of coercive means that is recognized in the powers of investigation and seizure of documents, regardless of their inculpatory or exculpatory value.

The only value or interest taken into account with special regimes of 'indiscriminate' access to all the confidential documentation available in the proceedings (even through the extensive protection of Article 33 (4) of the NRJC) is, in fact, the speed and procedural economy.

If the touchstone of the fragmentary conformation of interest in the protection of confidential information, in the ruling of practical agreement, is precisely the inculpatory or exculpatory value of that information, then the lack of differentiation of the access regimes to those documents lacks reasonableness and admissibility.

The special regimes of 'indiscriminate' access to all the confidential documents available in the proceedings sacrifice the best practical agreement of the potentially antagonistic interests of preserving business secrets and guaranteeing the exercise of the defense rights.

It is evident, from this chronology and brief analytical ${ }^{11}$ examination, that this quid juris provoked, in an insinuating but unsuspected way, a judicial activity difficult to transpose in all areas of economic regulation and supervision subject to the competence of the CRSC and in the sense that the litigation is generated, above all, by the size and importance of the ongoing sanctioning actions and proceedings. This activity and litigation in general are all the more useful when the judicial pronunciation is perceived to advance, sometimes, by unknown waters that require the decision maker to have something more than the usual line of coast navigation.

Fortunately, this challenge is shared by all procedural actors, albeit with different burdens.

To finish off and without prejudice to the critical syndication of the CRSC decisions, we can formulate some conclusions, relatively neutral or aseptic, in spite of the indications of the way forward:

\footnotetext{
${ }^{11}$ Always precarious for the omission of the specific contours of each appeal.
} 
i) The importance of the dialogue between the PCA and the CRSC in the establishment of interlocutory procedures of the sanction process;

ii) Any judicial ruling that affirms rights of defense against the administrative authority will imply legitimate reflexes in the speed of proceedings;

iii) The CRSC is not merely a regulatory body for the administrative legality of the sanctioning procedure.

As a post-scriptum or teaser of the next chapters, we did not resist the following provocation: the PCA, following the unfavorable sense of the decisions of cases 225/15 and 1/16, proposed an amendment to the NRJC, to the hitch of the Preliminary Project of the Private Enforcement Directive: ${ }^{12}$

Article 33

Access to the file

(...).

4 - Access to documents containing information classified as confidential is permitted only to the lanyer or external economic adviser of the defaendant and strictly for the purposes of the exercise of the defense in accordance with article 25 (1) and judicial challenge to the decision of the Competition Authority, and its reproduction, in whole or in part by any means, or its use for any other purpose, without prejudice to Article 12 (7), and Articles 14 and 15 of the [TRANSPOSITION PROPOSAL].

Where the law seemed to distinguish, it is now intended to deny access to business-value access regimes, irrespective of their inculpatory or potentially exculpatory value.

Is the stone still in the way?

\footnotetext{
${ }^{12}$ Which transposes the Directive 2014/104/EU of the European Parliament and of the Council of 26 November 2014, that currently corresponds to Law Project N. 101/XIII of the Commission for Economy and Public Works at the Portuguese Republic Assembly.
} 